\title{
EL MODELO ACADÉMICO DEL SABER UNIVERSITARIO Y SU CRÍTICA
}

\author{
por NELIY RICHARD \\ Ensayista, critica, directora de $\mathrm{B}$ \\ "Revista de Crítica Cultural"
}

\begin{abstract}
RESUMEN
Repensar críticamente el rol de la Universidad hoy significa preguntarse cómo incorporaren forma activa -dialogante e interpeladora a la vez- una diversidad de teorías y prácticas hasta ahora divorciadas del sistema cie validación académica, sea porque rebasan los convenios técnico-disciplinarios del conocimiento especializado, sea porque ponen en juego una exterioridad social negada por la falta de contexto del recinto universitario. Repensar críticamente el rol de la universidad significa abrir zonas de contactos entre esas referencias plurales que cuestionan la conformidad institucional del saber académico y sus jerarquías tradicionales.

El texto inscribe esta reflexión en el contexto chileno de los años del Régimen Militar y de la reapertura democrática.
\end{abstract}

Tácitamente entrelazados con los poderes en radicados cruces de palabras, los saberes son regulados por una política de los espacios que traza las fronteras de su reconocimientoy valoración sociales. Política de los espacios que ordena el reparto de estos saberes, distribuye sus contenidos, administra sus formas y controla el valor del lenguaje apropiado - d e llenguaje dueño y representante de una legitimidad social - según el territorio simbólico que define su pertinencia de habla. La máquina universitaria ejerce y defiende su autoridad institucional marcando el límite que distingue los saberes legítimos — autorizados — de los saberes 
ilegítimos, recluyendo a los primeros en el marco de las especializaciones disciplinarias:protegiendo el área reservada de estos saberes certificados del peligroso desorden de las hablas itinerantes o fugitivas que transitan en sus afueras sin la garantía de un domicilio conocido.

El resguardo del saber legítimo se ejerce delimitándolo y circunscribiéndolo al orden de las disciplinas que clasifican los objetos de estudio según reglas de especialización del conocimiento. El orden transmitido por las compartimentaciones disciplinarias refleja el modelo filosófico - la filosofía como modelo-que le dio forma al proyecto conceptual de una Universidad dividida en Facultades de ciencias y humanidades que debe regir universalmente la totalidad de lo enseñable ${ }^{1}$. Sólo que, hoy, las desarticulaciones y fragmentaciones del pensamiento filosófico moderno rompieron en mil pedazos estas ilusiones de totalidad y de universalidad del conocimiento.

Podrían invocarse muchas razones para justificar la necesidad de revisar tanto los fundamentos institucionales del saber universitariocomo los tics verbales que proceden de sus manías disertativas de generalidad y de universalidad. Todo el horizonte de nuestra contemporaneidad teórica está traspasado por el análisis de la práctica del discurso, de las técnicas y figuras del sentido, porque el lenguaje ha dejado de ser el vehículo confiible que expresaba homogéneamente referencias seguras, para volverse el campo minado de una relación entre sujeto y palabra sacudida por múltiples fracturas epistemológicas. ¿Por qué debería la lengua del saber universitario permanecer a salvo del efecto corrosivo y disolvente de esta radicalizada crítica del lenguaje, cuando ha sido ya demostrado que discurso, conocimientoy representación, siempreentrelazan poderes de dominación con fuerzas de denominación? ¿Por qué no analizar la lengua de la Universidad en el detalle de sus modalidades retóricas, de sus principios formales, de sus cálculos significantes, de sus resortes enunciativos, si reformular críticamente el pensamiento universitario implica problematizar la razón de su saber, y si toda problematización del saber pasa por una desconstruccióndel lenguajeque lo administra a través de ciertas regias de aceptabilidad $¥$ gramaticalidaddominantes?

'Dice Jacques Derrida, en una entrevista con Geoff Bennington titulada On colleges and philosopby, publicada en Postmodernism, London, ICA, Documento 4, 1986, p. 66: We have a pyramid in which philosophy, as a department, or spread through all the departments from the top of the pyramid, is supposed to define the objects and the fields of the whole institution, the whole building of the university [...] So the concept of the university is a philosophical concept,and the organisation of the university is a philosophical organisation. 
Toda la serie de ambigüedades, rupturas y desplazamientos de las categorías de sujeto, verdad y sistema, ocasionadas por esa crítica del lenguaje desplegada por la "escuela de la sospecha" bastaría para convencernos de la urgencia de revisar el modelo académico del disarso universitario, de interrogar su inmutable lógica de la coherencia y sus pretensiones de validez fundadas en ta continuidad e ilación de una lógica argumentativa que no puede ser distraída por ningún brillo estilistico, que no puede ser retardada por ninguna opacidad de razonamiento ni ambigüedad de vocabulario. Son varios los motivos para proceder a esta revisión, surgidos de los múltiples dislocamientos de los registros culturales de la modernidad y de su pensamiento filosófico. Pero la verdad es que en Chile son muchas otras las razones que además valen para someter el discurso universitarioa un análisis crítico de sus formas y operaciones, de las maneras que empleó —o desempleó-para atender los conflictos generados en torno a los signos de la crisis y a los signos de la crisis en un escenario histórico donde el pensar fue traspasado por la violencia totalitaria del robo del sentido y por el relato obstinado y rebelde de una reapropiación - e nplural - de los sentidos. ¿Cuál imagen proyectar hoy de una Universidad redemocratizadora que no sea la de una zona de contactos que reconjugue estos sentidos mediante cruces inéditos entre, por una parte, los saberes cualificados (regulares, sistemáticos, eficientes) del pensamiento universitario y, por otra, los saberes informales que se sublevaron contra el orden represor de su razón metódica?Discutirel significadode la Universidad como máquina gestionadora de discursos de conocimiento, es hacerse la pregunta crítica - enunciada por Foucault - de cómo "hacerentrar en juego los saberes locales, discontinuos, descalificados, no legitimados, contra la instancia teórica unitaria que pretende filtrarlos, jerarquizarlos, ordenarlos en nombre del conocimientoverdaderoy de los derechos de una ciencia que está detentada por unos pocos"2.

\section{La cita académicay sus otros}

Recuerdo con particular énfasis uno de los tantos eventos convocados para hacer del pensar un ejerciciode resistenciacrítica en el convulsionado paisaje de la Dictadura: un evento convocado por el Instituto Arcis (1986) que tuvo, entre ctras particularidades, la de ser casi la única circunstanciadurante todos estos años en la que se debatió a u n q u e con

- 2Foucault, Michel, “Cursodel 7 de enero de 1976", en Microfisica del poder, Las Ediciones de la Piquette,Madrid, 1979,p. 129. 
casi insostenible vehemencia - el tema del exilio. (Paréntesis 1: éste es uno de los temas de los que la Universidad de la postdictadura debió hacerse seriamente cargo. El destierro del pensamiento expulsado fuera del recinto de su tradición o fuera de Chile es parte de la historia fracturada de la pregunta sobre "¿Qué es hoy una Universidad nacional?"3. La respuesta no pasa sólo por el pragmatismode conciliarfórmulas burocráticas y administrativasde recontratación de los profesores expulsados. Se trata de dimensionar culturalmente el tema del exilio como una figura teórica de pensamiento crítico que obliga a reflexionar sobre las despertenencias históricas, sobre los traslados y choques de códigos de experiencias culturales, sobre las azarosas combinaciones de saberes en fuga de modelos que vivieron todos aquellos para quienes "lonacional" tuvo la aspereza de un corte hecho de múltiples desidentificaciones. Más que re-asimilar los cuerpos del exilio a la dudosa continuidad de los programas universitarios, más que re-familiarizarlos con lo mismo de siempre (las genealogías y fdiaciones de la autoridad académica, los ritos discipulares de la familia universitaria chilena), se trataría de recoger la fuerza de extrañeza-extrañamiento cultural contenida en las voces de quienes tuvieron que enfrentarse al desamparo del no lugar. se trataría de ocupar esa fuerza para crear metáforas capaces de desterritorializarel sentido de pertenencia-pertinenciaoficial demasiado anclado en la ntina académica de las disciplinas sedentarias).

Al traer a escena el recuerdo de ese evento convocado por el Instituto Arcis, hago de mi respuesta a la invitación de pensar el tema de la Universidad, de la relación entre el saber universitario y el entorno social de las prácticas culturales que se gestaron divorciadas de su modelo académico y que hoy deben ser reincorporadas al debate sobre la vigencia de ese modelo, algo no compatible con el modo universitario en el que se nos formulóla invitación. Y esa incompatibilidad de modos -de formas, de maneras de expresión — nos dice que la imagen de la Universidad como productora de discursos de saber puede también ser debatida a través de las cuestiones de estilos que separan nuestras prácticas.

Primero, al decir que "recuerdo"ese evento de 1983, introduzco una memoria subjetiva verbalizada en primera persona: esa primera persona traiciona la regla objetivadora del saber académico cuyo afán de sistematicidad se apoya en la in-defmición de la persona. Es la indefinición del

${ }^{3}$ Esta pregunta forma parte del temario sugeridoen la carta dirigida por la Vicerrectoria Académica y Estudiantil de la Universidad de Chile a los autores invitados a participar de la reflexión sobre la Universidad. 
neutro la que garantiza la abstracción del metadiscurso fdosófico o científico encargado de trascender el precario detalle de su contingencia enunciativa, de borrar los modos, tiempos, voces, números y personas, delatados por el accidente de género. Pero, hablando de géneros y de accidentes: uno de los recuerdos del evento del Instituto Arcis que busco hacer presente es el del filósofo chileno Patricio Marchant, escenificando una de sus reiteradas críticas al discurso universitario desde el temblor emotivo, el pánico corporal, la gestualización de la falla, es decir, desde todo lo negado por la maestría del saber filosófico: el cuerpo mismo y sus vicisitudes que burlan la ilusión superior del Yo trascendente de la filosofía con la imagen del filósofo caído de las alturas, habiendo tropezadocon la revelación terrenal de su cuerpoinconfesable, de un cuerpo que sobraal hacerse notar mediante reacciones psico-fííicas que colocan al Yo de la enunciación en un primer plano de señales involuntarias, de señales obscenas por temblorosas (es decir, por femeninas) cuando toob el ritual de la autoridad académica busca poner a su sujeto en situación de tener que sostener un discurso firme viril —acerca de la verdád última de las cosas. Lo "impresentable"de la presentación de Marchant era lo que él mismo llamó "el cuerpo", y que el modelo académico del saber filosófico o científico reprime por indecente, elimina por perturbador y escandaloso: "Cuerpohay ahí donde una terrible, imperiosa, inaguantable necesidad se impone, se presenta -ella - . Cuerpo es necesidad; no todo cuerpo es necesario, pero todo lo necesario es cuerpo. Cuerpo hay ahí donde el desciframiento de una serie de síntomas revela, de pronto, la conexión profunda que secretamente ha guiado toda una vida. Cuerpo hay ahí donde un deseo, que se oculta para que se lo descubra, tiembla ser descubierto, tiembla no ser descubierto. [...1 Cuerpo es pensamiento necesario. Descubrir cómo está construida, qué fuerzas están en juego, en la necesidad implacable. Respecto a ésta, la necesidad lógica, formal aparece apenas como simple curiosidad ${ }^{4}$, decía P. Marchant. Y fue la formalidad de esa necesidad lógica cultivada por el rigor académico del saber adecuado-transmisible como una verdad del saber y un saber de verdad - la que castigó el libro Sobre árboles y madres, de P. Marchant ${ }^{5}$, marginándolohasta hoy de los estudios universitarios, de la filosofía y de la literatura chilenas. La somatización de la falla en el cuerpo vivo de P. Marchant anticipaba el gesto teorizado en su libro de convertir el lapsus

\footnotetext{
4Marchant, Patricio, "Discurso contra los ingleses", en Revista de Critica Cultural, N², Santiago, noviembre de 1994, p. 4.

5Marchant, Patricio, Sobre árboles y madres, Ediciones Gato Mur, Santiago,1984.
} 
y la errata en artificios retóricos de un discurso que se quiso titubeante: "un anti-discurso universitario" expuesto a ser juzgado desde el acto fallido, desde el doble sentido de la palabra errar: cometer un error, vagar sin rumbo. Errancias y desvíos, los del texto de P. Marchant, que corrompen el recto ideal de corrección de la demostración - de-saber apoyada en una "lógicade la erección, de la posición y la verdad"6. Una lógica incapaz de valorar lo inexacto - lo incierto, lo imprevisiblecomo riesgo creativo de quienes eligen la pluralidad sinuosa $y$ confusa de conceptos-metáforasy no la unicidad clara de las verdades demasiado finitas del pensamiento-teorema. El discurso universitario7 sancionó Sobre árboles y madres como un libro "de-generado"8 por ser el libro que es: un libro inclasificable (que transgrede las delimitaciones de géneros académicamente re-conocidas) y también un libro de perversiones que rompe exhibicionistamente el protocolo académicodel cuerpo de menos $\rightarrow$ del cuerpo en retirada- de una filosofia universitaria que hace sistema con la actual "deserotizaciónde la Universidad y de los espacios intelectuales" 9 .

Me traslado a otraintervención de la misma escena, que también tuvo lugar en el encuentro del Instituto Arcis: la del poeta Gonzalo Muñoz leyendo un texto - luego repartido en fotocopia - que trazaba las condiciones de emergencia de la escena crítica desplegada en los alrededores de la literatura y de las artes visuales de los '80 en Chile ${ }^{10}$. Escena de escritura teórica - quizás la más osada de todas - que surgió de una demoledora "crisisde la toma de la palabra" cuando, "a partir del entrecortamiento, del quiebre de toda historia narrable", las narraciones poé-

\footnotetext{
6Oyarzín, Pablo, "Traición,tu nombre es mujer", en Ver desde la mujer, Olga Grau (editor), La Morada/Cuarto Propio, Santiago,1992, p. 151.

'valdría la pena, sin duda, ponderar la generalidad de tal denominación efectuando todos los matices del casopara cumplir con la "necesidadde una enorme cantidadde distinciones, precisiones, protocolos de lecturas, establecimientos de largas series, marcas de rupturas aparentes o reales; necesidad de estudiarel modo, la forma, las condicionesmateriales, las energías libidinales, rodos los supuestos, las escenas, los gestos que constituyen al discurso filsófico universitariocomo tal", según señalaba P.Marchant en su libro ya citado (p.102). Pero, lo que aquí se denomina "discursouniversitario"se refiere a lo que dominantemente se escribe "en las Universidades contemporáneas como filosofía.tesis, ensayos, papers, etc.".

§Vicuña, Miguel, “¿Una autobiografía fantástica?,en El Espiritu del Valle, № 1, Santiago,diciembre de 1994, p. 71.

9Ferrer, Christian, 'Melodías, sonetos, papers", en "Últimasfunciones del ensayo", dossier publicado por la revista Babel, N² 18,Buenos Aires, agosto de 1990, p. 23.

10Para un análisis crítico del conjuntode prácticas asociadasa la "escena de avanzada" " "nueva escena" de los '80 en Chile, consultar Brito, Eugenia, Campos minados, Etitorial Cuarto Propio. Santiago,1990; y Richard, Nelly, Margins and institutions, Melbourne, Art and Text, 1987.
} 
ticas se doblaron sobre sí mismas para "postularel excedente utópico de la letra" 11 y revertir - con sus desbordes — la condena nacional a la verdad regimentada y uniforme, a la penuria del sentido $y$ a la indigencia de sus vocablos. En aquel documento, G. Muñoz hizo brillar la estética crítica del arte y de la literatura de los ' 80 dedicados a la búsqueda -urgida y urgente - de una palabra de no rendición cuando "soledady deterioro eran las heridas de acceso al lenguaje propio"12. No habría cómo recrear las circunstancias que opusieron radicalmente el afuera al adentro de la Universidad en los tiempos de la Dictadura, sin pasar por estas "heridas" de los textos de extramuros: heridas ligadas al transitar de nombres y conceptos por zonas de alto riesgo, por los bordes más disgregados del mapa cultural en la peligrosa compañía de obras todas ellas extremas en su gesto de repensarse políticamente en el vacío de representaciones y de significaciones fiables, de ideologías confiables. Pero aquí va una pregunta: ¿Cómo habilitar la cita de un texto como el de G. Muñoz para una necesaria reflexión sobre el modo en que discurso académico y discurso anti-académico dramatizaron sus conflictos teóricosy políticos en el pasado reciente, si dicha cita aún permanece relegada a la única condición de ser que la hizo posible: la de la fotocopia? ¿Cómo traspasar la fragilidad de esa cita al rígido sistema de las "normaseditoriales" cuyas exigencias aparecen formuladas en el documento que acompaña la solicitud de textos que nos dirige la Universidad para este mismo número de los "Analesde la Universidad de Chile",si todo en dicha cita rechaza la formalidad de ese sistema: desde el desgaste material de su impresión gráfica hasta su borrosa memoria aún clandestina y residual?

Evoco esta intraducibilidad de la cita para hablar de un pasado cultural no completo sin la referencia estremecida a cómo el discurso universitarioy el discurso anti-universitariovivieron entonces sus años de más rotundo antagonismo, porque no sólo nos dice de las dificultades contenidas en la tarea de juntar saberes y prácticas ayer divorciados por el corte represivo y hoy todavía sin reconciliarse porque la precariedad de su rango documental sigue chocando con la demanda universitaria de un corpus articulado por un sistema de validación del saber que se justifica en la norma editorial del crédito bibliográfico. Hay también una no traducíbilidad de las prácticas discursivas enfrentadas por la mención a esa cita que resulta conflictiva cuando el saber oficial busca reglamentar

\footnotetext{
${ }^{11}$ Muñoz, Gonzalo, Escritura de una escena, documento fotocopiadode su intervención en el seminario del institutoArcis.

${ }^{12}$ Ibid.
} 
el formato de sus encuentros con los ctros saberes no reglamentarios, imponiéndoles su normalidad-normatividadde edición. Una de las recomendaciones publicadasen el documento de las "normaseditoriales"que acompaña la invitación a escribir este texto dice lo siguiente: "El título debe contener el máximo de palabras que definan el contenido del artículo. En el caso de que se quiera usar un título de fantasía, es necesario incluir un segundo título, subordinado, que sea explicativo del contenido"13.

La definicióny explicación del contenido deben precisar el objeto del discurso, rectificando así lo que la fantasía de un "título de fantasía" pudiese contener de vago, de di-vagante: de sospechosamente otro respecto del modelo técnico de operatividadque domina, hoy, la relación práctica entre disciplinas académicas y mercado de las profesiones. Para el modelo académico de un saber racionalizado por la lógica expositiva de la demostración-desaber, el "contenido"es el núcleo substancial de la verdad del saber mientras la forma es el in-substancial decorado que se pierde $\rightarrow$ se derrocha - en artificios, en metáforas. El enredo de las metáforas que proliferan en las orillas de los discursos consistentes es juzgado perverso por la ley de gravedad-seriedaddel contenido que dota al saber de su equilibrio racional. Esa tradición es la que castiga la in-consistencia del estilo como decorado, la superficie decorativa de la forma que es llamada a la razón por una economía de la profundidad del contenido, de la claridad y de la exactitud referenciales, apoyada en la demostración lógica de una tesis cuyos argumentos deben resumirse en la síntesis del título para acortar así el paso entre escritura y pensamiento: para no dejar que la oblicuidad significante de la metáfora lleve el sentido a desviarse de la meta representada por una verdad que debe resistir las tentaciones del "placerdel texto" (Barthes).

El requisito de un lenguaje claro y directo que sostenga el hilo de la argumentación conceptual sin caer en el laberinto metafórico de los "como si" apoya un modelo dominante de saber tecno-operativo que rechaza la ambigüedad de los dobles sentidos como traición al punto fijo de la verdad. El sistema de las "normas editoriales" cuya policía de la forma regula la disposición del sentido, da cuenta de ese modelo de saber que la práctica universitaria fija como standard discursivo, y da también cuenta de la "hipótesis represiva" que hace pesar ese modelo sobre el pensamiento teórico-cultural gestado durante la última década en Chile,

${ }^{13}$ Documento "Analesde la Universidad de Chile -Vi serie- Normas Editoriales",adjuntoa la carta de invitación dirigida a los autores por la Universidad. 
que teorizó su polémica diferencia con el saber universitario(sus convenciones disciplinarias, sus formatos discursivos, sus ritos institucionales) en un estiloque resulta todavía "intratable,inaguantable"(Marchant) para la universidad tradicional.

\section{Pluralidad de saberesy mezclas teóricas}

Repensar la Universidad en el contexto de una sociedad y de una cultura postdictatoriales que encuentran en trance de redefiniciones - afectadas ambas por la pérdida de nitidezy consistencia de sus lineamientos de sentido- implica medir críticamente la función de esta Universidad como institución académica: es decir, como productoray legitimadorade discursos de conocimiento aún ritualizados por la imagen de la Universidad tradicional como única depositaria del saber autorizado. Pensar la Universidad hoy es repensarla desde "latensión entre un saber legitimado, regular, y una pluralidad de saberes irregulares"14 que han recorrido ¥ siguen recorriendo- los márgenes de la instituciónuniversitaria para arriesgar en ellos juegos de lenguaje y de pensamiento capaces de descentrar el canon de la cultura académica.

Esa "pluralidadde saberes irregulares"surgióen Chile alrededor de las prácticas estéticas més innovadoras y cuestionadoras de la cultura no oficial de los ' 80 , y fue conjugada por lo que Rodrigo Cánovas llamó el "discurso de la crisis"15. Discurso cuyas op ciones teóricas y cuyos materiales culturales estuvieron indeleblementemarcados por la convulsión del sentido, el dislocamiento de las referencias de identidad, las roturas de la máquina de representación social y el estallido de sus nexos simbólico-comunicativos. Ese "discursode la crisis" se tramó en redes completamente ajenas a las universitarias, incluso muy distanciadas del intento de aquellos profesores que permanecieron dentro de la Universidad buscando la "recuperaciónde la imagen universitaria a través de un trabajo de excelencia académica"16 principalmente consistenteen defender su vínculo a una cierta contemporaneidad teórico-literaria que los salvara del oscurantismo cultural. De hecho, ese trabajo se delineó en base a cotos de autorreferenciaacadémica que protegían el saber especializado de la hostilidad del afuera reforzando la clausura de sus léxicos

\footnotetext{
14Oyarzún, Pablo, Fragmentos de una conversación con Adriana Valdés en tomo a la Universidad, en revista Io, NQ1, Santiago, noviembre de 1992, p. 24.

${ }^{15}$ Cánovas, Rodrigo, "Hacia una histórica relación sentimental de la crítica literaria de estos reinos”,en Cuentas hispanoamericanos, Madrid,Septiembre de 1990, p. 165.

${ }^{16}$ Ibid.
} 
subordinados a las clasificaciones disciplinarias, aislando sus modelos teóricos de las pugnas ideológicóculturales que animaban las obras en el conflictivoespacio de la disidencia política, separando estas obras de la violencia de los choques que ellas mismas desataban para fracturar el marco de su institucionalidadartística o literaria, desvinculandoel pensar crítico de las batallas de signosque se libraban en torno a la reconceptualización de nuevas formas de "politización del arte" (Benjamín) que le hicieran frente ala contingencia. Obligada por la fuerza de las circunstancias a sostener un dudoso principio de no-interferencia camuflado tras el supuesto de una pureza metodológica que dejaba de lado la exterioridad social, esa crítica universitaria se fue ensimismandoen formas retraídas y sustraídas del campo de fuerzas en el que las prácticas culturales se armaban de valor para contraponer su gesto de rebeldía al conformismo pasivo de las instituciones. Opuesto a ese tecnicismo formal del saber académico que autocensuraba "la relación entre las estructuras lingüísticas y las otras estructuras (sociales, ideológicas, mentales)", el "discurso de la crisis"exploró las zonas más obturadas del imaginariosimbólico de los '80atravesando fronteras de géneros -discursivas y sexuales - que conectaban la mirada sobre las obras con la trama semiótica del mismo poder que las violentaba. Esta nueva producción teórico-cultural chilena de los '80se largó a la aventura de una experimentación con el sentido mediante teorizaciones heterodoxas que mezclaban referencias omitidas por el discurso universitario (Benjamín, el psicoanálisis; Foucault, la desconstrucción, etc.) con lo censurado-reprimido del paisaje local en una transgresora combinación de estratos psíquicos ocultos y de metáforas prohibidas. Este proceso de intenso desmontaje crítico del sentido llevado a cabo por un "discursode la crisis"que cuestionaba la rutina del saber canónico con sus experimentaciones limítrofes de citas fracturadas por un saber hecho "parahacer tajos"(Foucault), desestabilizóel lenguaje de los macrodiscursos elaborados por los viejos y nuevos centros de producción académica, incluyendo los centros de estudios de la sociología alternativa ${ }^{17}$.

La tensión generada entre ese nuevo "discurso de la crisis" y los modelos tradicionales de saber filosófico y científico practicados dentro de la Universidad o en los centros académicosde investigaciones sociales aludía, de hecho, al enfrentamiento entre dos registros de conocimiento: por un lado, el saber regular y certificado de las disciplinas establecidas que basan su eficiencia en el manejo técnico de una racionalidad demos- 
trativa y explicativa y, por otro, los saberes irregulares y no certificados (sin el aval de una pertenencia disciplinaria) que circulan fuera de las zonas sagradas y se aventuran en regiones transversales donde se deshacen y se rehacen localmente los conceptos "a partir de un horizonte móvil, de un centro siempre descentrado, de una periferia siempre desplazada"18; saberes que vagan alrededor de la pregunta por la verdad del conocimiento con definiciones en suspenso y gramáticas inconclusas. Por un lado, los lenguajes a salvo de los textos que circulan sin riesgo al estar protegidos por la autoridad doctrinal de sus repertorios clasificados, y por otro, las poéticas del desarreglo que rompen la fila de los léxicos convalidados por el mercado técnico de las especializaciones y cuyo indisciplinamiento formal tiene el valor político de cuestionar el sentido regimentado de las disciplinas institucionales.

Sin duda que los saberes informales del "discursode la crisis" fueron mucho más sensibles que las macro-teorizacionescientíficas y filosóficas al quiebre de las iíneas rectas y a la desintegraciónde los puntos fijos que caracterizan nuestra experiencia latinoamericana de una modernidad en crisis. Son ellos los que reconjugaron más perceptivamente en Chile las failas de la razón moderna - unificadora y sistematizadora - desde lenguajes todos ellos habitados por el temblor de la incertidumbre que reniega delas verdades categóricas, la desbandada de nombres y conceptos fugados de las líneas demasiado fijas del reticulado de la competencia del saber académico. Son estos saberes nómades los que recogieron la creatividad dispersa de las prácticas estéticas que anticiparonlas mutaciones de la sensibilidad cultural del Chile de la transición, que prefiguraron dichas mutacianes mientras que disciplinas más constituidas como la Sociología se encontraban demasiado inhibidas por su pacto racional con la modernidad para aventurarse en la encrucijada teórico-cultural de la nueva red crítica de los "post".Estos saberes nómades —atravesadospor la desconfianzahacia las totalizaciones de los macrodiscursos y el finalismo ideológico de los significados últimos y trascendentes - proponían mezclas teóricas y flexiones escriturales que desbordaban enérgicamente el masco del saber reglamentado por el discurso universitario.

Soñar el modo en que la Universidad podría hoy reconectarse con la sociedad —on las imágenes de multiplicidad y diversidad sociales que acompañan la reconquista de una práctica democrática - pasa por la pregunta de cómo atravesar los límites del saber universitariomultiplicando en su interior conexiones lateralescon las energías críticas surgidas de

${ }^{18}$ Cánovas, Rodrigo, Literatura chilena y experiencia autoritaria, Flacso, Santiago, 1986, p. 18. 
la pluralidad fragmentaria de teorías locales nacidas, todas ellas, del residuo y de la mezcla. Teorías localmente marcadas por la heterogeneidad de conocimientos parciales aprendidos desordenadamente en ias brechas culturales que separan las disciplinas cerradas sobre sí mismas. La defensa de esa heterogeneidad de saberes oblicuos a reincorporar pluralistamente a la enseñanza universitaria supone un nuevo modelo de conocimiento él mismo capaz de interrogar sus propias convenciones discursivas, una razón ella misma dispuesta a criticar el molde filosófico de su fundamentación de orden, un saber él mismo interesado en revisar el mito de su abstracción universal. (Paréntesis 2: si hay un instrumento crítico que podría hoy contribuir a esta reformulación democrática del pensamiento universitario, es la teoría feminista. Es ella la que ha denunciado más radicalmente los subterfugios de una tradición filosófica del saber que oculta el modo en que un dispositivo de representación hegemónica —el de la masculinidad occidental — detenta el monopolio de la verdad basado en el falso supuesto de la transparencia de los códigos, de la neutralidad e impersonalidad del conocimiento, de su indiferencia a cualquier diferencia de género, clase o raza. Desde la problemática sexual de la discriminaciónde género, la teoría feminista ha radicalizado su crítica a la abstracción universal del conocimiento, a su idealización como saber absoluto que debe trascender cualquier contexto material de experiencia. Ha develado el saber en su condición de saber siempre relativo, local y parcial, contingente, cuya práctica no puede desligarse materialmente de las complicidades de intereses tramados por el deseo de mantener o de suprimir las oposiciones de sexo, clase o raza, que dividen su composición institucional. Quizás sea porque la crítica feminista del conocimiento subvierte una de las bases más mistificadoras de la filosofia del saber universitario como saber presuntamente neutro, puro y desinteresado, que dicha crítica sigue mayoritariamente excluida del proyecto de la Universidad, aun cuando "pareceya inadmisible que en las instituciones académicas, consideradas como el lugar de elaboración, de intercambio, de difusión y de diseño de estrategiasde aplicación del saber, estén ausentes o escasamente presentes todos los aportes teóricos y metodológicos" procedentes de la crítica cultural feminista) ${ }^{\mathbf{1 9}}$.

Desidealizar el conocimiento rompiendo la ficción de lo abstracto-ge-

19Para una reflexión sobre las tensiones críticas entre la "nueva escena" y el disaurso de las ciencias sociales, consultar Richard, Nelly, La insubordinación de los signos, Ecitorial CuartoPropio, Santiago, 1994; y Brunner, José Joaquín, "Las tribus rebeldes y los modernos",en Bienvenidos a la modemidad, Editorial Planeta, Santiago, 1994. pp. 261-268. 
neral para dejar que lo concreto-singular irrumpa como accidenteen las sistematicidades monótonas de la verdad científica o filosófica, exige revisar los protocolos discursivos de su obligación de coherencia hoy desañados, entre otras cosas, por el universo de la tecnocultura y sus estéticas massmediáticas, por "lasimbólica dispersa, heteróclita y eclosiva del video clipy del spot que remueven las operaciones educativasbásicas que se encuentran en el acápite 'Objetivos Generales del Curso', tales como: desarrollar la capacidad de razonamiento, argumentabilidad, asociatividad, jerarquía, discriminalidad, selectividad, causalidad, concordancia, motricidad, etc." ${ }^{20}$. La sobreoferta de retóricas visuales y narrativas desplegadas por el entorno socio-estético de las comunicaciones masivas y las nuevas conductas tecnoperceptivas estimuladas por la sobreexposición de imágenes, han producido un desplazamiento de las fronteras entre "razón e imaginación, ciencia y arte, naturaleza y artificio"21 que trastocan las jerarquías tradicionales de la cultura ilustrada, poniendo así en cuestión la academiciáad de un saber basado en los ritos bibliográficos del culto libresco. Ia reorientación democratizadorade una práctica universitaria del saber supone desjerarquizar la referencia obligada a la cultura superior basada en la centralidaddel libroy abrir el juego de las citas a materiales vivos de lectura nacidos — promiscuamente - de intersecciones cotidianas entre subjetividad social y formas de vida, imaginarios urbanos y sintaxis corporales, políticas y estéticas del consumo, etc. Esto rompería la distancia epistemológica entre sujeto y objeto consagrada por la tradición idealista en su defensa de una autonomía y trascendencia del "yo" superior del conocimiento, y contaminaría esa distancia con mixturas culturales de prácticas heterogéneas que cruzan múltiples contextos enunciación. Estos actos multi-teóricosforman parte de toda la serie de desplazamientos que los nuevos programas de crítica universitaria asumen transdisciplinariamente, o antidisciplinariamente: 'Loque queremos hacer no es simplemente interdisciplinariedad, lo que implica objetos y competencias ya identificados [...] Queremos descubrir objetos todavía no identificados. En los bordes de diferentes disciplinas, aparecen nuevos objetos producidos por nuevas situacionestec nológicas, económicas, históricas- y les damos prioridad a estos nuevos objetos que no requieren simplemente de una competencia dada, sino

${ }^{20}$ Deleuze, Guilles, Différence et répétition, Editions de Minuit, París, 1968, p. 3 fa traducción es nuestra).

${ }^{21}$ Grau, Olga, “Presentación”en Verdesde la mujer,Editorial La Morada/Cuarto Propio,Santiago, 1992, p. 14. 
que requieren un nuevo entrenamiento para una nueva competencia", decíaJacques Derrida al formular el proyecto de su ColegioInternacional de Filosofia ${ }^{22}$ donde ella es llamada a desconstruir su saber del saber.

Liberar las potencialidades críticas de las múltiples operaciones de lectura que se traman en las junturas o disjunturas de prácticas marginales y desobedientes, implica convocaren tomo a ellas saberes no domesticados por los convenios académico-disciplinarios del mercado técnico ni por sus leyes de aceptación y transabiíidad dominantes: saberes diseminados en los bordes inferiores (cotidianos y populares) del mapa de legitimación simbólica que tradicionalmente rebaja a nivel de subcultura los formatos híbridos y los vocabularios bastardos de géneros impuros; saberes ínfimoseíntimos-de plieguesy dobleces, de costuras al revéstejidos en la constelación metafórica de "lo femenino" como región a desesclavizar de "la tiranía de los discursos globalizantes"(Foucault); saberes minoritarios y disidentes que potencian nuevas subjetividades sociales ubicadas en las orillas de la cultura oficial; saberes crítico-reflexivos que desprograman la economía funcional del conocimiento rentable y sus lógicas meramente ejecutivas ${ }^{23-24}$.

22Thayer, William, preinforme sobre el documento"Los desafios de la educación chilena frente al siglo xx", Universidad Metropolitanade Ciencias de la Educación.

${ }^{23}$ Martin-Barbero, Jesús, "Nuevosmodos de leer", en Revista de Crítica Cultural, N² 7, Santiago, noviembrede 1993, p. 19.

${ }^{24}$ Derrida, Jacques, op. cit. 


\section{A PROPÓSITO DEL ARTÍCULO \\ DE NELLY RICHARD}

Resulta ineludible, en relación a este texto, intentar hacer una sucinta referencia a un tiempo de trabajo intelectual universitario muy dificil y durante el cual la ambigüedad fue la característica del espacio.

Efectivamente, la intervención de las Universidades, y en especial de la nuestra, trajo como consecuencia inmediata la represión de toda reflexión crítica en su interior. Por cta parte, una generación intelectual, formadaprincipalmente en las diversas vertientes del pensamiento de los ' 60 y '70,como también muy influida por el proceso de Reforma, se vio excluida de toda la participación social que esos discursos señalaban.

Basta, como ejemplo, el significado de la exoneración académica en Facultades de principal desarrollode un pensamiento crítico, como Artes y Filosofía.

Sin embargo, ya a partir de 1975 se empiezan a generar diversos organismos que, en el margen o fuera de toda institucionalidad oficial, van a jugar el rol de estudio y producción de un pensamiento que, inserto en una apremiante situación, se caracterizó por su alto nivel conceptual y analítico.

En el plano cultural general se llamaron FLACSO, Taller Artes Visuales (TAv), c.E.N.E.c.A., Taller 666, entre otros.En cuanto lo universitario, aparece en la Universidad de Chile, primero, una organización estudiantilllamada A.C.U. (Agrupación Cultural Universitaria), y pronto, convocada principalmente por el filósofo exonerado Jorge Millas y el biólogo Luis Izquierdo, la Asociación Cultural y Universitaria Andrés Bello. Ésta tuvo como característica la de constituirse en un espacio de frontera, puesto en evidencia por su misma integración -de universitarios exonerados y otros que conservaron sus cargos académicos-, y cuya tarea principal fue la de atender la necesidad de supervivencia de una reflexión y un discurso universitario. Todos estos organismosfueron responsables de la generación de una verdadera "UniversidadInformal", nombre que pareció el más definitorio y que otros identificaron como "UniversidadExtramuros".

Es en este contexto que los artistas visuales, principalmente, y los teóricos de Arte —entre ellos, en forma relevante, Nelly Richard —, generaron puntos de encuentro y debate, que en lo fííico fueron TAV, Galería Sur y Espacio Cal, y que en lo simbólico se constituyeron en el espacio 
posible de reconocimientoe intercambio. La característica más relevante de la producción generada fue la de constituir un trabajo experimental donde el cuestionamiento de los lenguajes ocupó la axialidad principal. Inmersos en una realidad donde se forzaba un corte cultural profundo, desconcertados ante la brutal caída de un proyecto que resultaba altamente identificatorio para muchos, la duda se establecía en el valor referencia1 del nombre y de todo sistema de significación; de ahí la necesidad de abrir los bordes de lo nombrado y dar preeminencia a los ejercicios de desplazamiento y metáfora, en un proceso de negatividad sucesiva que permitió nuevas formas de habla. Cuestionándose el valor d ela representación, se valorizó principalmenteel significante. Se podría hablar de un trabajo que forzaba la redesignación y que, por lo mismo, operaba críticamente sobre el concepto de institucionalidad del lenguaje, y con ello, de toda cra posibilidad de institucionalidad. De hecho, durante este tiempo, la producción de Arte más importante se dio fuera del espacio universitario formal.

Hacia mediados de los '80, este impulso empieza a decaer hasta casi desaparecer.

Por una parte la ampliación del espacio político, por otra el efecto del proyecto educacional cultural - q u e por su corte desarrolló una generación más complaciente-, o el desconcierto ante los grandes cambios en las posibles sociedades alternativas, ahogaron ese espíritu crítico que constituyó el espacio universitario informal. Pero, tal vez la razón más profunda es la que nos dice la dificultad de recordar, y hacernos cargo, de una vida problemática o problematizadora: de asumir la posibilidad de la contradicción sin la cual, paradojalmente, no es fácil imaginar a la Universidad.

Francisco Brugnoli 